\title{
Chronic obstructive pulmonary disease - stopping smoking: It is never too late
}

\author{
Douglas MC Wilson MD CCFP FCFP \\ Director, McMaster Stop Smoke Clinics, \\ McMaster University, Hamilton, Ontario
}

Smoking is the main cause of chronic obstructive pulmonary disease, and the function of the lungs in smokers deteriorates with time at a much faster rate than in nonsmokers or ex-smokers. Smokers with chronic lung disease can often function better, breathe more easily and cough less, just by stopping smoking. They require less medication (puffers, etc) and the deterioration of lung function is slowed. Within $24 \mathrm{~h}$, the amount of carbon monoxide in the lungs and blood returns to normal, allowing more oxygen to supply body functions.

\section{Why do I smoke?}

Smokers continue to smoke for many different reasons. Some say it stimulates them, others say that it helps them to relax; they like the taste, they do it out of habit, associating it with coffee and alcohol, and to relieve stress - they also enjoy the social aspect of smoking with other smokers. Unfortunately, when they stop, most smokers experience craving and irritability, which increases the longer they go without a cigarette.

\section{Are you thinking about quitting?}

Think about your reasons for smoking and write them down. Now think about how smoking is not good for you and write those down. What are your pros and cons of quitting? Think about health, money, your family and the risks of continuing to smoke.

\section{Planning to quit}

Have you tried to quit before? How long did that last? What made you start smoking again? What can you learn from those attempts? Keep track of your smoking for a few days. What are your triggers? Do you smoke after meals, with coffee, alcohol, breaks, friends, in stressful situations? Plan how you will cope with these urges. Are there triggers you can avoid for a while, such as meeting with friends who smoke? Can you go for a walk after meals? Shower on awakening instead of smoking? Can you drink more water, chew gum or suck on cinnamon sticks? With every behaviour change, reward yourself. Find a buddy who will support and encourage you. 


\section{Set a quit date}

Pick a date within the next three weeks that you would like to set as your first smoke-free day. The night before, enjoy your last cigarette, then destroy the rest. Enjoy your new smoke-free lifestyle.

\section{There is help out there}

Your family physician can help you. You may benefit from the nicotine patch and/or nicotine chewing gum. The nicotine patch and gum help to control uncomfortable withdrawal cravings without giving you the other 4000 chemicals of tobacco smoke that cause lung and heart disease. Your doctor may prescribe Zyban for you if there are no medical reasons not to. Both will bring nicotine levels to the brain, helping to gradually cure your addiction. Start this treatment on your quit date. Zyban is a non-nicotine pill that stimulates a 'feel good' chemical called dopamine. It takes one to two weeks to produce the levels of dopamine that you are used to with tobacco smoke. We suggest that you set your quit date for the 10th day since starting Zyban. Continue an active program for at least three months.

\section{Quitting may not be easy}

In fact, it may be the most difficult behaviour change you will ever make, but it is the most rewarding. Use positive self-talk. Remind yourself of the reasons you want to quit for good. Don't let temptations or even a slip stop you from quitting. Aim for a life of smoke-free breathing, with a smoke-free home, car, etc. Relapse is often associated with alcohol, and exposure to smokers, so be careful not to set yourself up. Encourage other smokers in the household to stop; convince them that they will be helping themselves as well as you. Stress is unavoidable, but use other healthier ways of coping with stress such as walks, music or whatever works for you. Take one day at a time.

Good luck!

This information should not be used as a substitute for the medical care and advice of your physician. There may be variations in treatment that your physician may recommend based on individual facts and circumstances. This information may be reproduced without permission and shared with patients and their families. 


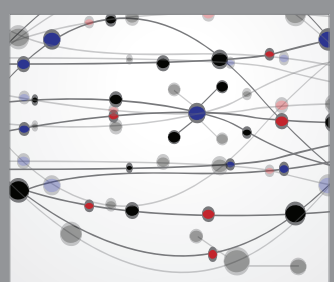

The Scientific World Journal
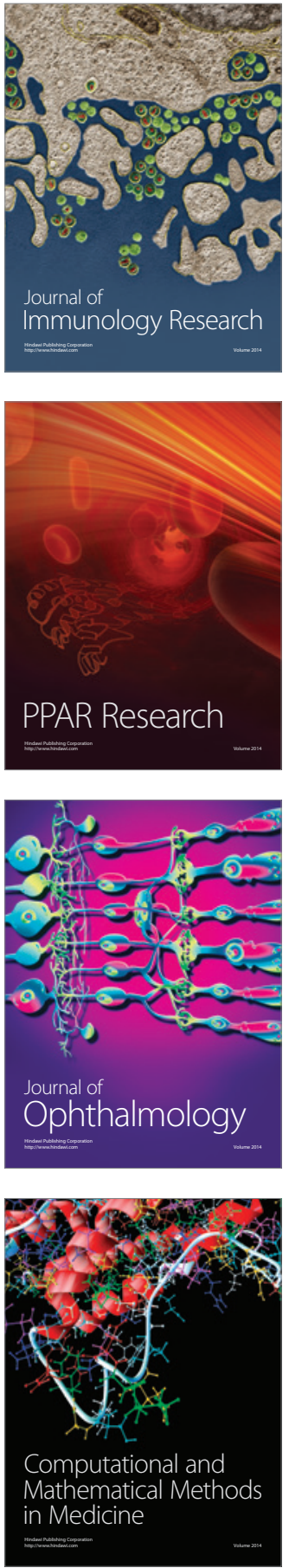

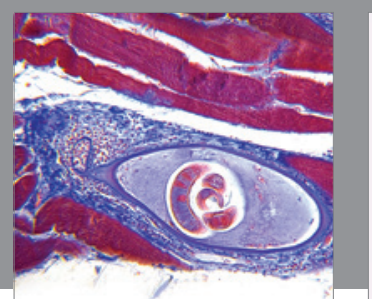

Gastroenterology Research and Practice

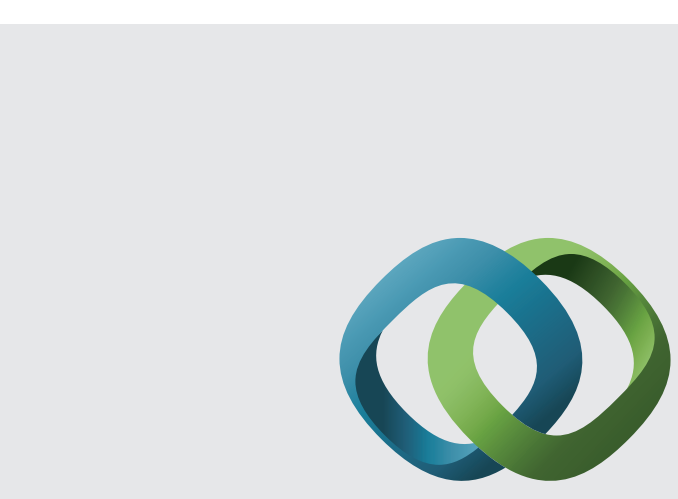

\section{Hindawi}

Submit your manuscripts at

http://www.hindawi.com
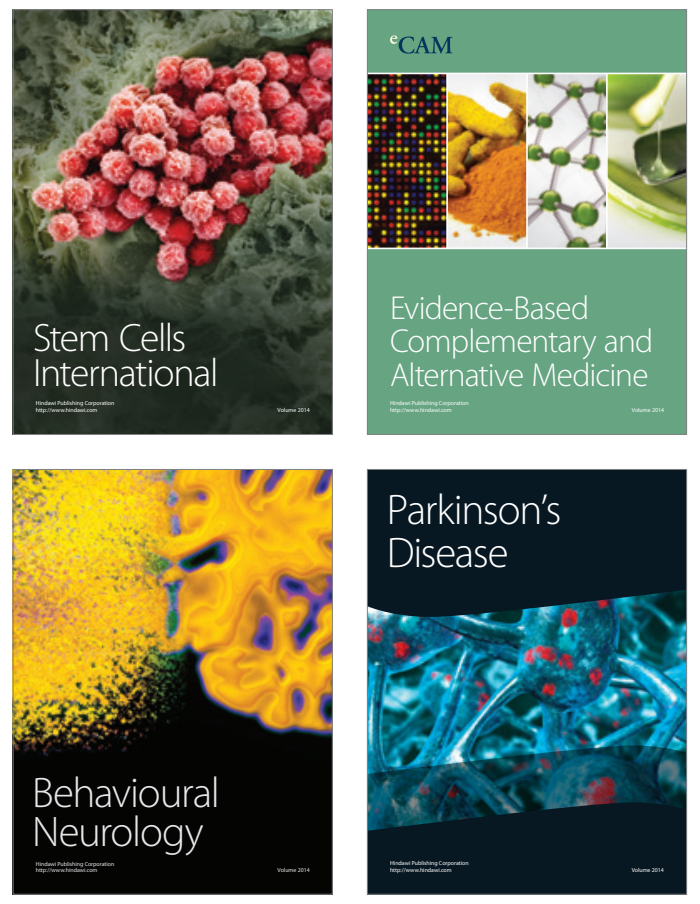
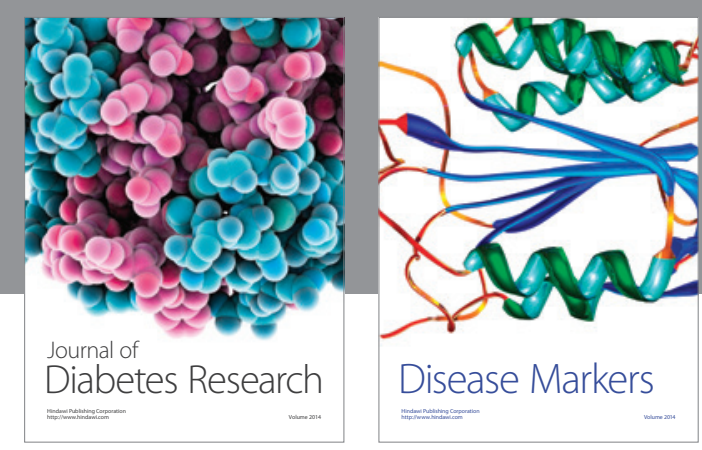

Disease Markers
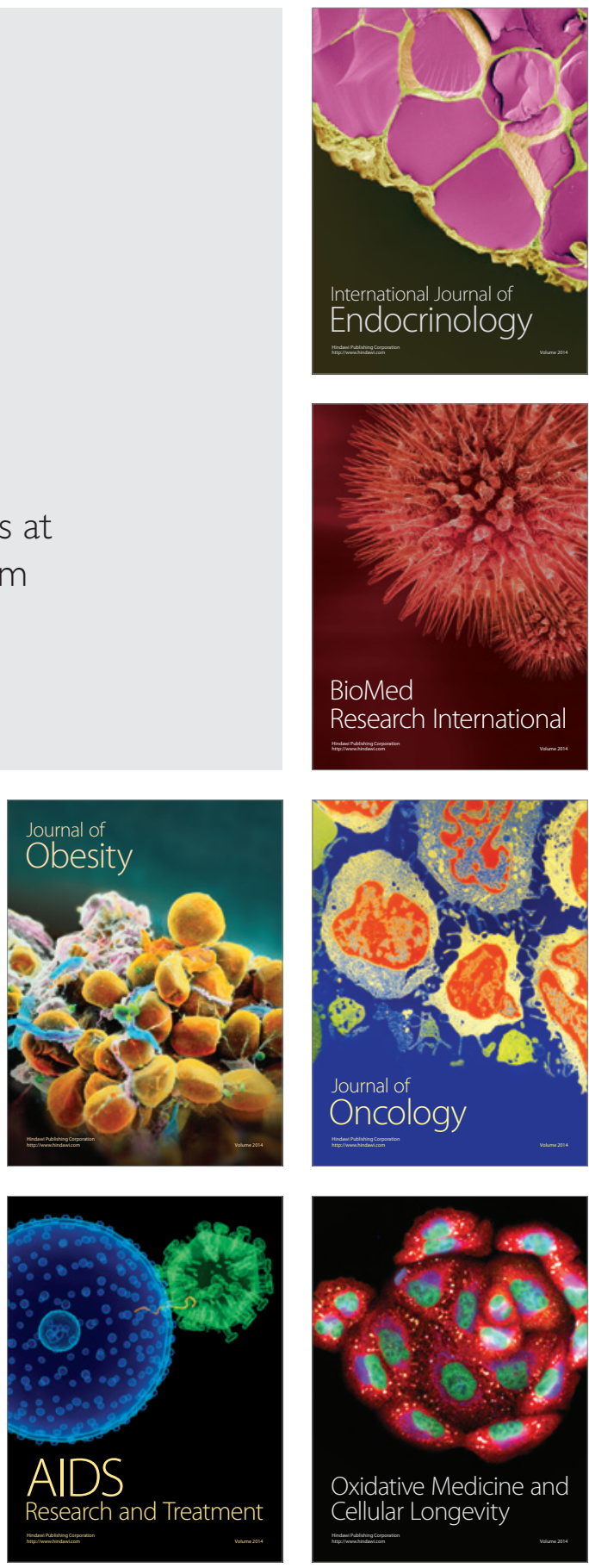